\title{
Big Shoes to Fill at A Challenging Time
}

\author{
Tonglei Li'
}

Published online: 26 July 2020

(C) Springer Science+Business Media, LLC, part of Springer Nature 2020

This is my first editorial as your editor-in-chief and I would like to take the opportunity to say thank you. Thank you to the leadership at the AAPS and Springer-Nature for the recognition and trust in me. Thank you to Dr. Peter Swaan and to Dr. Wolfgang Sadée for encouragement and help during the transition into this leadership role. And thank you to the readers, the authors, and the reviewers of Pharmaceutical Research for contributing in various ways to the journal over the last 35 years. I am looking forward to working with you all to drive this research forum to flourish continuously.

This is a challenging time. As the pandemic has wreaked havoc on the world and put societies into a halt, wepharmaceutical scientists - would feel more obliged in advancing science and drug treatment against this emerging and other complex diseases. This is also a changing time, much faster than before, in disseminating and sharing research findings. When this journal was founded in 1984, it would be mind-blowing to think of retrieving a research paper on a "smartphone." The ease in submitting a manuscript to a large section of peer journals does seem to undermine the stature enjoyed by this journal for many years. Often, I heard from colleagues and students wondering about what is the focus of this journal.

The vision of Pharmaceutical Research can still be best described by one of Dr. Wolfgang Sadée's editorials in 1986 as "poised at the crossroads between the physicochemical sciences and the biological sciences" of drugs, diagnosis, and therapy [1]. It was later echoed by Dr. Vincent Lee in 2008 when he passed on the baton to Dr. Peter Swaan that the journal should serve the community by publishing papers that integrate "fundamental principles in chemistry, biology, and

Tonglei Li

tonglei@purdue.edu

Department of Industrial \& Physical Pharmacy, College of Pharmacy, Purdue University, West Lafayette, IN 47907, USA engineering for creating and evaluating" drug products and treatments [2]. What has also been instilled into the core of Pharmaceutical Research is publishing papers that are mechanism-based and hypothesis-driven.

I share the vision and will work with my fellow editors to ensure this forum stays as a forerunner in serving the AAPS and the drug development community in general. As the business of pharmaceutical industry is mainly driven by innovation, traditional boundaries between drug development and discovery and clinical assessment become even more blurred, thanks to the advance and integration of individual disciplines, as well as exponential buildup in knowledge. The need for interdisciplinary research is more imperative, as drug products become more complex, multi-component, and even involve live cells or tissues. I hope Pharmaceutical Research will help promote research along this direction.

A personal favorite with that regard is multiscale modeling and simulation in bridging a product design and its behaviors in a biological environment. Because of the astonishing development in computing power, storage capabilities, and availabilities of various databases ranging from molecular structures and properties to materials characterization and to clinical trials, using computation to model and simulate ADME processes in conformity with the product makeup should and will play a more important role. Multiscale modeling and simulation permits integration of concurrent biological and physicochemical processes to explore the PK/PD space, which is difficult to do with a laboratory device. As PBPK (physiologically based pharmacokinetics) and QSP (quantitative systems pharmacology) have advanced from the clinical side (or top-down should we think how a drug product traverses in the body), there is a great need in developing and utilizing computational approaches to investigate how a drug delivery system acts at the local site of release and absorption, and, importantly, integrate with a more grainer approach such as PBPK in order to predict the whole-body exposure and efficacy. 
At last but not the least, I would like to welcome new Editor, Professor Richard A. Gemeinhart, from University of Illinois at Chicago (UIC), where he is Associate Vice Chancellor for Research and Professor of Pharmaceutics and Bioengineering. Prof. Gemeinhart has led a research group focused on hypothesis-driven research in polymeric materials science, physicochemical interactions of molecules with polymers, and biologically inspired materials design since 2001. Recent emphasis of the group has been in understanding the influence of excipients on biologic function, striving in the long-term to develop predictive models of excipient biologic 'function'. He earned his B.S.E. from the Department of Interdisciplinary Engineering and earned his Ph.D. degree from the Department of Industrial and Physical Pharmacy, both at Purdue University. Prof. Gemeinhart continued his postdoctoral training at Cornell University in the School of Chemical Engineering. As AVCR and Research Integrity Officer for UIC, Prof. Gemeinhart has additional interest and expertise in research misconduct review, specifically plagiarism, falsification, and fabrication, and training in responsible conduct of research.
As we all hope the normalcy will soon return, we need to work even harder and advance the science of medicine. Pharmaceutical Research - both the discipline in general and this journal - being at the interface to translate a drug molecule into a disease-treating product shall explore all necessary means and knowledge in the translation.

Stay healthy and safe!

Tonglei Li

Editor-in-Chief

\section{REFERENCES}

1. Sadée W. Pharm Res. 1986;3:1.

2. Lee HLV. Shaping the transformation of pharmaceutical science. Pharm Res. 2008;25:2707-12.

Publisher's Note Springer Nature remains neutral with regard to jurisdictional claims in published maps and institutional affiliations. 